\title{
Transient hippocampal down-regulation of Kv1.1 subunit mRNA during associative learning in rats
}

\author{
Saïd Kourrich, ${ }^{1}$ Christine Manrique, ${ }^{1}$ Pascal Salin, ${ }^{2}$ and Christiane Mourre ${ }^{1,3}$ \\ ${ }^{1}$ Laboratoire de Neurobiologie des Processus Mnésiques, UMR 6149 CNRS-Université de Provence, Marseille, France; ${ }^{2}$ Interactions \\ Cellulaires, Neurodégénérescence et Neuroplasticité UMR 6186-Université de la Méditerranée, Marseille, France
}

\begin{abstract}
Voltage-gated potassium channels $(\mathrm{Kv})$ are critically involved in learning and memory processes. It is not known, however, whether the expression of the Kvl.1 subunit, constituting Kvl channels, can be specifically regulated in brain areas important for learning and memory processing. Radioactive in situ hybridization was used to evaluate the content of Kvl.1 $\alpha$-subunit mRNA in the olfactory bulb, ventral, and dorsal hippocampus at different stages of an odor-discrimination associative task in rats. Naive, conditioned, and pseudoconditioned animals were sacrificed at different times either prior to a two-odor significance learning or after odor discrimination was established. Important decreases of Kvl.1 mRNA levels were transiently observed in the ventral hippocampus before successful learning when compared with the pseudoconditioned group. Moreover, temporal group analysis showed significant labeling alterations in the hippocampus of conditioned and pseudoconditioned groups throughout the training. Finally, Kv1.1 mRNA levels in the hippocampus were positively correlated with odor-reward association learning in rats that were beginning to discriminate between odors. These findings indicate that the Kvl.1 subunit is transiently down-regulated in the early stages of learning and suggest that Kvl channel expression regulation is critical for the modification of neuronal substrates underlying new information acquisition.
\end{abstract}

Voltage-gated $\mathrm{K}^{+}(\mathrm{Kv})$ channels play an important role in regulating neuron excitability. Although their primary function is to stabilize membrane potential, they can also regulate cell firing and information transfer rates to effectively prevent hyperexcitability in neuronal networks. The Kv1 channel, one of four subfamilies identified (Kv1-Kv4), consists of four primary subunits, which can be further classified as cloned subunits. At least five $\alpha$ subunits (Kv1.1-Kv4, Kv1.6) are highly and diversely expressed in the limbic system (Kues and Wunder 1992; Sheng et al. 1993, 1994; Wang et al. 1994; Veh et al. 1995; Rhodes et al. 1997; Monaghan et al. 2001). A large variety of Kv1 channel blockers are available, making it possible to discriminate between the various $\mathrm{K}^{+}$currents. Unfortunately, these blockers recognize several Kv1 subunits and not one subunit only (Stühmer et al. 1989; Grissmer et al. 1994; for review, see Coetzee et al. 1999; Harvey 2001). However, they facilitate the investigation of Kv1 channel physiology (for review, see Robertson 1997; Song 2002). The pharmacological blockage of Kv1 channels increases the duration of action potential, and as a result, voltage-gated $\mathrm{Ca}^{2+}$ channels remain open for a much longer period of time, thereby increasing the amount of neurotransmitter released from presynaptic terminals (Meir et al. 1999; Cunningham and Jones 2001; Monaghan et al. 2001). Moreover, inactivation of presynaptic Kv1 channels in vitro can significantly affect activity-dependent mechanisms involved in spike-broadening, and thus powerfully regulate synaptic efficacy in hippocampal slices and in the medial nucleus of trapezoid body slices (Geiger and Jonas 2000; Dodson et al. 2002; Dodson and Forsythe 2004). The heteromer channels containing $\mathrm{Kv1.1/Kv1.2}$ and $\mathrm{Kv} 1.1 / \mathrm{Kv} 1.6$ are involved in such regulatory actions (Dodson et al. 2002).

Enhanced synaptic transmission and a reduction in $\mathrm{K}^{+}$conductance can increase behavioral efficiency on tasks requiring learning and memory processes. Indeed, a correlation has been

\section{${ }^{3}$ Corresponding author.}

E-mail mourre@up.univ-mrs.fr; fax 33-4-88-57-68-04.

Article and publication are at http://www.learnmem.org/cgi/doi/10.1101/ Im.86305. found in hermissenda between reduced $\mathrm{K}^{+}$currents and learning (Alkon 1984, 1999). Futhermore, in Drosophila, a genetic shaker mutation of Shaker A-type $\mathrm{K}$ channel inactivation produces learning impairment in olfactory conditioning (Cowan and Siegal 1986). In mammals, conditioning can cause significant reduction of $\mathrm{K}^{+}$currents (Sanchez-Andres and Alkon 1991; Schreurs et al. 1998). A reversible antisense inhibition of Kv1.1 channel expression impaired associative memory in rodents (Meiri et al. 1997; Gratacos et al. 1998). Moreover, Kv $\beta 1.1$-deficient mice suffered an impaired learning in a water-maze task. The loss of Kv $\beta 1.1$, an auxiliary subunit that confers fast inactivation on otherwise noninactivating Kv1.1 channels, leads to a reduction of frequency-dependent spike broadening (Giese et al. 1998, 2001). A transient increase in paired pulse facilitation in the piriform cortex evoked by afferent fiber stimulation in vitro is related to enhanced learning capabilities following odor-discrimination training. This facilitation was followed by a persistent reduction in $\mathrm{K}^{+}$currents that returned to baseline values after $5 \mathrm{~d}$ (Saar et al. 1999). The inhibition of Kv1 activity by 4-diaminopyridine was found to reduce $\mathrm{K}^{+}$currents and improve memory task performance in old rats (Barnes et al. 1989). In a recent study, Kourrich et al. (2001) showed that kaliotoxin, a selective blocker of Kv1.1 and Kv1.3 channels, facilitated learning processes, but not longterm storage of an odor-reward association in an olfactory task. In concordance, these observations support the idea that Kv1 channels, in particular, one containing the Kv1.1 subunit, essentially participate in the regulation of neurotransmitter release, and consequently synaptic efficiency during learning and memory processes. Moreover, the physiological modulation of Kv1.1 channels seems to be orchestrated, in principal, by synergistic actions of protein kinases (Drain et al. 1994; Boland and Jackson 1999; Manganas and Trimmer 2000; Winklhofer et al. 2003). Relatively little is known, however, about physiological regulation of Kv1 channel genes during these two processes.

The aim of the present study was to analyze possible variations in Kv1.1 subunit expression during associative learning. We used an odor-discrimination task in rats because (1) kaliotoxin 
improves learning performance in this task (Kourrich et al. 2001), and (2) the expression of the activity-regulated immediately early gene c-fos (which is used as an "activity marker" and a "marker of changes in gene expression") changes during a two odordiscrimination learning task. Dorsal hippocampal fields are differentially activated during specific stages of learning (Hess et al. 1995; Gall et al. 1998). Although dentate gyrus labeling remained stable throughout learning, c-fos hybridization levels were enhanced in areas CA1 and CA3 fields, and were highest in CA3 during the initial learning of an odor pair when compared with overtrained rats (Hess et al. 1995; Gall et al. 1998). We show here that the level of Kv1.1 mRNA transiently decreases throughout associative learning, and that significant changes in levels occur in the ventral hippocampus prior to changes in the dorsal hippocampus. Furthermore, we also showed that Kv1.1 mRNA expression is positively correlated with learning on a memory task.

\section{Results}

\section{Acquisition of the odor-reward association}

During the associative olfactory task, conditioned animals improved across sessions prior to their sacrifice. The comparison of percent correct responses indicated a significant difference between the second and third sessions (ANOVA, $F_{(1,21)}=4.759$, $P<0.05)$ (Fig. 1A). A significant latency difference between positive stimulus $(\mathrm{S}+)$ and negative stimulus $(\mathrm{S}-)$ was observed in session 3 as revealed by ANOVA $\left(F_{(1,8)}=6.805, P<0.05\right)$, but not in session 2 (ANOVA, $F_{(1,34)}=0.404$, NS). This significant discrimination was due to a decrease in the time taken to respond to positive stimulus, and an increase in response time to negative stimulus (Fig. 1B). The cumulative time decreased over sessions (Fig. 1C), indicating successful procedural learning aspects of the associative task.
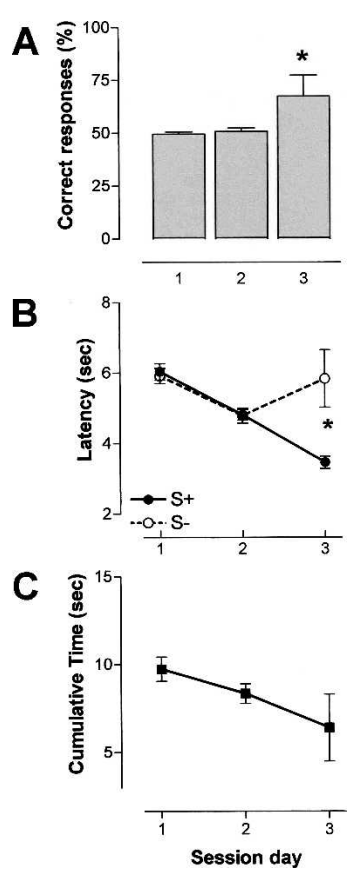

Figure 1. Odor-reward training. Mean performance obtained across three 60 -trial sessions. The intertrial interval was $15 \mathrm{sec}$. (A) Correct response rate \pm S.E.M. (in percent); $(B)$ Latencies \pm S.E.M. (in seconds). S+ and $S$ - latencies were recorded for the positive and negative odor stimulus, respectively; (C) cumulative time \pm S.E.M. (in seconds). Note the significant discrimination of the two odors in the third session. $\left(^{*}\right)$ $P<0.05$ (session 2, $n=18$; session $3, n=5$ ).
Table 1. Kv1.1 mRNA levels in the anterior olfactory nucleus

\begin{tabular}{lccc}
\hline $\begin{array}{l}\text { Mean } \pm \text { S.E.M. } \\
\text { (\% Naive) }\end{array}$ & $\begin{array}{c}\text { Naive } \\
\text { group }\end{array}$ & $\begin{array}{c}\text { Pseudoconditioned } \\
\text { group }\end{array}$ & $\begin{array}{c}\text { Conditioned } \\
\text { group }\end{array}$ \\
\hline Session 2-1 h & $100.0 \pm 2.3$ & $112.3 \pm 6.1$ & $109.4 \pm 3.8$ \\
Session 2-4 h & $100.0 \pm 3.1$ & $111.7 \pm 4.3$ & $125.9 \pm 4.9$ \\
Session 3-1 h & $100.0 \pm 10.3$ & $108.9 \pm 11.3$ & $112.2 \pm 5.6$ \\
\hline
\end{tabular}

\section{Kvl.1 in situ hybridization}

Animals from the three experimental groups (naive, pseudoconditioned, and conditioned) were decapitated at different times as follows: $1 \mathrm{~h}$ after the second session, $4 \mathrm{~h}$ after the second session, and $1 \mathrm{~h}$ after the third session. In total, two in situ hybridization (ISH) experiments were performed, the first to compare Kv1.1 expression in different groups at a given time (comparison of mRNA levels between the groups) and the second to analyze the temporal pattern (time course) of Kv1.1 mRNA expression for a given experimental group (temporal analysis). The statistical comparisons were performed from brain sections hybridized in the same experiment and autoradiographed using an identical film sheet.

Figure 2 shows examples of the specific ISH signal patterns observed in the parietal and occipital cortices, ventral posteriomedial thalamic nucleus, geniculate nuclei, red nucleus, and hippocampal formation. In the hippocampus, Kv1.1 mRNA expression was weak in the pyramidal layer of the CA1 field, whereas the signal was intense in the pyramidal layer of the CA3 field and in the granular layer of the dentate gyrus. In contrast, the olfactory bulb contained a weak Kv1.1 mRNA amount in the internal granular layer (data not shown).

\section{Comparison of Kvl.1 mRNA levels between the groups}

In the examination of olfactory pathways, an analysis was performed on regions believed to be necessary for the learning and memory of olfactory associative tasks (olfactory bulb, Ammon's horn, and dentate gyrus) (Chaillan et al. 1999; Truchet et al. 2002), as well as in the three animal groups (naive group, pseudoconditioned group, and conditioned group). The Kv1.1 mRNA level was analyzed in the olfactory bulb and in three structures of the dorsal and ventral hippocampus (dentate gyrus, CA3 and CA1) of rats sacrificed at three stages of learning, i.e., $1 \mathrm{~h}$ after session $2,4 \mathrm{~h}$ after the session 2 , and $1 \mathrm{~h}$ after session 3 .

Kv1.1 ISH labeling was not altered in the internal granular layer of the olfactory bulb, regardless of the task session or sacrifice time (ANOVA, $F_{(2,35)} \leq 2.876$, NS) (Table 1). In contrast, the mRNA level varied in the hippocampal formation (see below).

\section{Stage: $1 \mathrm{~h}$ after the session 2 (Fig. 3)}

Statistical analysis of data from the ventral hippocampus indicated a significant decrease of ISH labeling for each structure analyzed, that is, the conditioned group in comparison with the pseudoconditioned and naive groups (ANOVA, $F_{(2,35)} \geq 3.802$, $P<0.05)$. In both the dentate gyrus and CA3 field, Kv1.1 mRNA expression was significantly decreased in the conditioned group compared with that of the pseudoconditioned group $(-40 \%$, $P=0.049$ and $-35 \%, P=0.047$, respectively). Messenger RNA levels for the conditioned group also decreased $(-37 \%,-30 \%$ respectively) in comparison with that of the naive group, but this decrease was not significant. Furthermore, no variation between the pseudoconditioned and naive groups was found. In the CA1 field, however, the mRNA levels were significantly lower in the conditioned than in both the pseudoconditioned $(-44 \%$, Scheffé, $P=0.044)$ and the naive $(-47 \%$, Scheffé, $P=0.018)$ groups.

\section{Learning \& Memory}


A

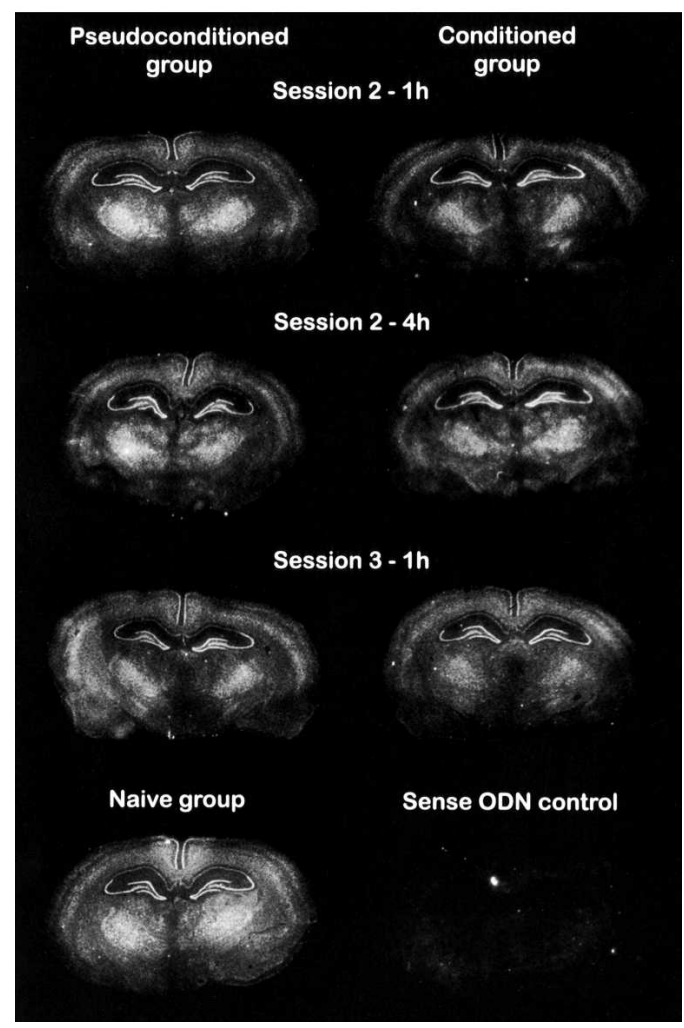

B

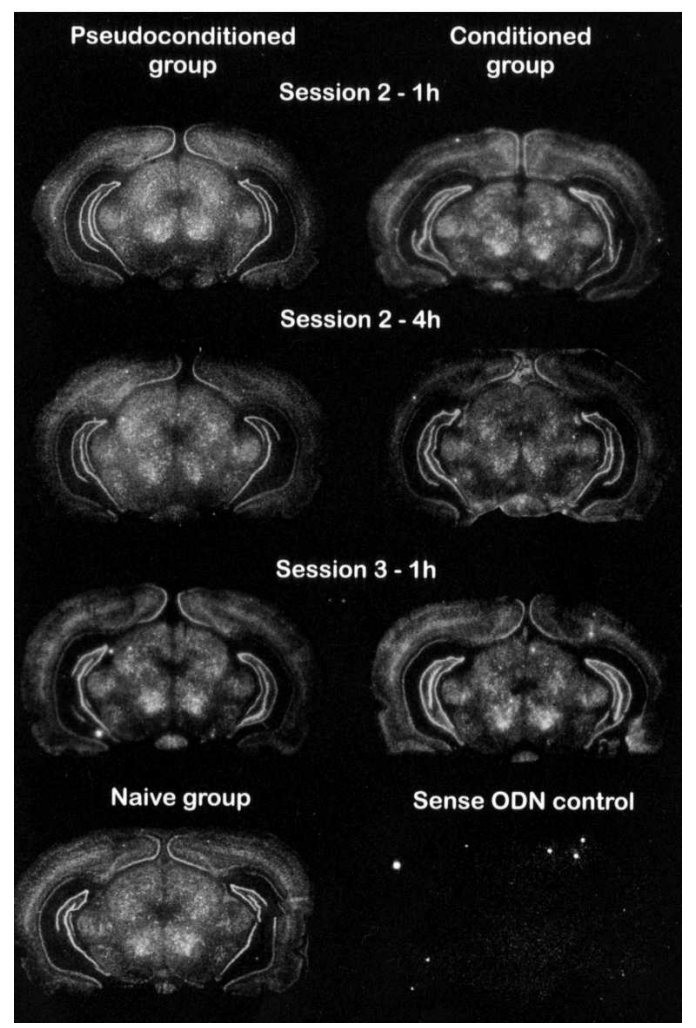

Figure 2. Representative distribution of Kv1.1 mRNA in the rat hippocampus of three experimental groups, i.e., naive, pseudoconditioned, and conditioned groups. (A) Dorsal hippocampus; $(B)$ ventral hippocampus. The rats were sacrificed 1 or $4 \mathrm{~h}$ following session 2 or $1 \mathrm{~h}$ following session 3. Kv1.1 mRNA signals were revealed by autoradiographic in situ hybridization using a specific antisense probe labeled with ${ }^{35} \mathrm{~S}$. Brain regions were defined according to Paxinos and Watson (1986). White pixels represent a high mRNA-labeling level, while black pixels, no labeling.

In the dorsal hippocampus, statistical analysis indicated no significant variation of Kv1.1 mRNA levels between each of the groups for the three analyzed structures $\left(F_{(2,35)} \leq 1.506, \mathrm{NS}\right)$.

\section{Stage: $4 \mathrm{~h}$ after the session 2 (Fig. 4)}

In the ventral hippocampus, a difference in mRNA expression was found in the CA1 field (ANOVA, $F_{(2,33)}=3.687, P<0.05$ ) with a significant decrease in the conditioned group compared only with that of the naive group $(-31 \%$, Scheffé, $P=0.047)$. No difference in Kv1.1 mRNA levels were found in both the dentate gyrus and CA3 field.

In contrast, in the dorsal hippocampus, Kv1.1 mRNA expression showed significant variations in the three regions examined (ANOVA, $F_{(2,33)} \leq 3.459, P<0.05$ ). The Kv1.1 mRNA level decreased between the conditioned and the naive groups for the dentate gyrus, CA3, and CA1 field $(-38 \%,-28 \%$, and $-37 \%$, Scheffé, $P=0.018, P=0.042$, and $P=0.046$, respectively). ISH labeling in the dorsal hippocampus for the conditioned group was weaker than that of the pseudoconditioned group, (CA1, $-26 \%$, CA3, $-11 \%$, and Dentate gyrus, $-40 \%$ ), but this difference was not significant.

\section{Stage: $1 \mathrm{~h}$ after the session 3 (Fig. 5)}

In the ventral hippocampus, Kv1.1 mRNA levels in the dentate gyrus and CA3 field were similar between the three groups (ANOVA, $F_{(2,31)} \leq 2.668$, NS). In contrast, a significant change in the mRNA level was observed in the CA1 field (ANOVA, $\left.F_{(2,29)} \leq 3.554, P<0.05\right)$. The Kv1.1 mRNA expression in the con- ditioned group CA1 field was significantly increased (+48\%) when compared with that of the naive group (Scheffé, $P=0.048$ ), but not to that of the pseudoconditioned group.

In the dorsal hippocampus, ANOVA indicated a significant difference in the dentate gyrus $\left(F_{(2,31)}=4.438, P<0.05\right)$, but not in the CA1 and CA3 fields $\left(F_{(2,31)} \leq 0.919\right.$, NS). The Kv1.1 mRNA level in the dentate gyrus of the pseudoconditioned group was decreased in comparison to that of the naive group ( $-35 \%$, Scheffé, $P=0.025$ ). However, no relative variation was found in the conditioned group.

\section{Temporal analysis (Fig. 6)}

The aim of this analysis was to study potential variations in Kv1.1 mRNA levels throughout a learning and memory task in a given experimental group with a given brain structure. All compared data was obtained from autoradiograms on the same film sheet.

Throughout the odor-discrimination task procedure, Kv1.1 mRNA amounts increased in the olfactory bulb, especially in the pseudoconditioned group (ANOVA, $F_{(2,15)}=6.931, P<0.01$ ). The Scheffé analysis indicated an increase $4 \mathrm{~h}$ after session 2 , which remained throughout session 3 , compared with $1 \mathrm{~h}$ after session $2(+22 \%, P \leq 0.02)$. No variations of mRNA levels were statistically observed for the conditioned group. No labeling variation was found in the dorsal CA1 field of the hippocampus for both groups (ANOVA, $F_{(2,15)} \leq 2.312$, NS). In the ventral CA1 field, the Kv1.1 mRNA level significantly increased in the pseudoconditioned group, whereas no differences were observed in the conditioned group (ANOVA, $F_{(2,15)}=4.340, P<0.05 ; F_{(2,15)}=1.802$, NS, respectively). ISH level increase in the ventral CA1 field was 


\section{Session 2 - 1 hour}

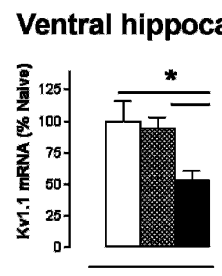

CA1 field

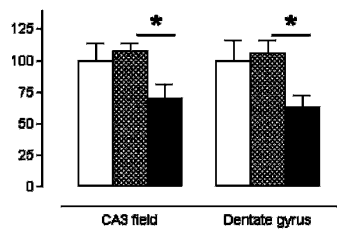

Dorsal hippocampus
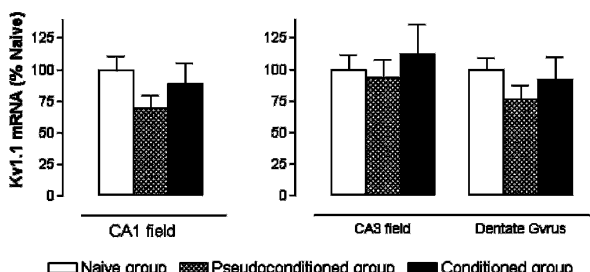

$\square$ Naive group Pseudaconditioned group Conditioned group

Figure 3. $\mathrm{K} v 1.1$ subunit mRNA levels, measured $1 \mathrm{~h}$ after session 2 , for ventral and dorsal hippocampus regions. Data expressed as mean \pm S.E.M. Statistical significance: $\left({ }^{*}\right) P<0.05$ in ANOVA comparing the naive $(n=6)$, pseudoconditioned, $(n=6)$, and conditioned $(n=7)$ groups.

particularly observed following session 3 (+16\%, Scheffé, $P=0.033)$. In the CA3 field, regardless of group or dorsal/ventral location, the ISH level did not vary during odor-discrimination learning (ANOVA, $F_{(2,15)} \leq 2.457$, NS). In contrast, if no variation was found in the dorsal part of the dentate gyrus, a significant decrease in Kv1.1 mRNA levels were detected in the ventral part $4 \mathrm{~h}$ after session 2 in the conditioned group (ANOVA, $\left.F_{(2,15)}=11.067, P<0.001\right)$. Furthermore, this observed decrease persisted throughout session $3(-22 \%$ and $-22 \%$, Scheffé, $P=0.013$ and $P=0.001$, respectively).

\section{Analysis of Kvl.1 mRNA level in relation to behavior}

To examine potential relationships between behavior and Kv1.1 mRNA levels during the olfactory discrimination task, we performed linear regression at specific stages of learning, and in particular, where statistical differences in ISH labeling between rat groups were observed (i.e., $1 \mathrm{~h}$ after session 2 for the ventral hippocampus). At $1 \mathrm{~h}$ following session 2 , the regression line between $\mathrm{S}$ - stimulus performance and Kv1.1 mRNA levels of the three ventral hippocampus structures was significant (Fig. 7, $\left.F_{(1,5)} \geq 6.996, P<0.05\right)$. Moreover, correct response for $\mathrm{S}-$ stimulus was also correlated with the mRNA level in the dentate gyrus, CA3, and CA1 fields of the ventral hippocampus $\left(F_{(1,5)} \geq 6.617, P<0.05\right)$. In contrast, where there was a zero slope, no significant correlation was found for S+ stimulus, global correct response, and cumulative time (Fig. 7) regardless of structures studied $\left(\mathrm{F}_{1.5} \leq 1.521\right.$, NS). Odor discrimination was evaluated by an S+ and S - latency analysis and the latency difference was correlated significantly with mRNA levels in the dentate gyrus and CA3 field of the ventral hippocampus $\left(F_{(1,5)} \geq 6.901\right.$, $P<0.05)$, but not in CA1 field, although the line slope showed a positive relationship between latency differences and mRNA levels (Fig. 7). No significant regressions were found between the other learning stages and brain structures (data not shown).

\section{Discussion}

Learning and memory processes during an odor-reward associative task led to a decrease in Kv1.1 subunit mRNA in the hippo- campus. More precisely, the results suggest that the decrease in mRNA expression (1) occurs when rats begin to learn odorreward association, (2) appears foremostly in the ventral rather than dorsal hippocampus, and (3) is transient because no mRNA level differences between conditioned and pseudoconditioned rats were observed once learning stabilized in session 3. Moreover, the Kv1.1 mRNA level was positively correlated with learning.

The distribution of Kv1.1 subunit mRNA in the experimental group was consistent with previous studies showing a high level in the CA3 field and dentate gyrus, and a low level in the CA1 field, olfactory bulb, and neocortex (Kues and Wunder, 1992; Wang et al. 1994; Hallows and Tempel 1998). Subcellular localization of Kv1.1 protein in the hippocampal formation was found to be localized primarily on axon and terminal regions of mossy fibers afferents, Schaffer collaterals, and in the entorhinal cortex (Monaghan et al. 2001). However, dendritic Kv1.1 subunit was observed in some brain structures, such as the apical dendrites of pyramidal cells throughout the neocortex (Wang et al. 1994; Veh et al. 1995).

Behavioral performance on olfactory associative discrimination was similar to our previous reports (Fournier et al. 2001; Kourrich et al. 2001). During session 2, the animals did not learn the two-odor significance, as they rapidly responded to both the S+ and S - stimuli. In conditioned animals, Kv1.1 mRNA levels were decreased in both the ventral and dorsal hippocampus at 1and 4-h intervals following session 2, compared with pseudoconditioned and naive animals, respectively (Table 2). Following session 2, however, no Kv1.1 mRNA level differences were detected between pseudoconditioned rats exposed to the same stimulus level compared with water restricted naive rats. This suggests that exposure to odors, water, and light pulses was not sufficient to generate the observed decreases in Kv1.1 mRNA, but rather reflects pure learning processes. Because the stimuli were not significant for pseudoconditioned rats, the decrease in Kv1.1 mRNA suggests modifications of neuronal excitability balance during training.

Throughout session 3, the animals showed a preference for $\mathrm{S}+$ stimulus, and did not respond to $\mathrm{S}-$ stimulus; at the same

\section{Session 2 - 4 hours}

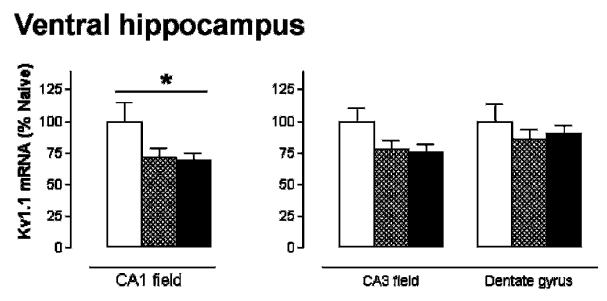

\section{Dorsal hippocampus}

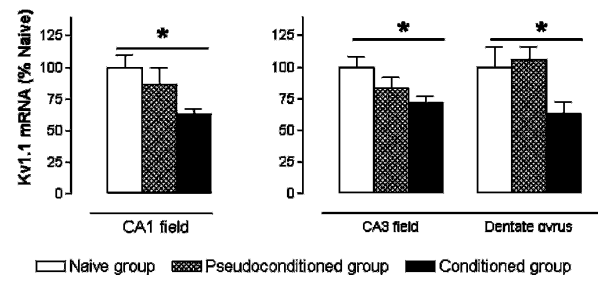

Figure 4. Kv1.1 subunit mRNA levels, measured $4 \mathrm{~h}$ after session 2 , for ventral and dorsal hippocampus regions. Data expressed as mean \pm S.E.M. Statistical significance: $\left({ }^{*}\right) P<0.05$ in ANOVA comparing the naive $(n=6)$, pseudoconditioned, $(n=6)$, and conditioned $(n=6)$ groups. 


\section{Session 3 - 1 hour}

\section{Ventral hippocampus}
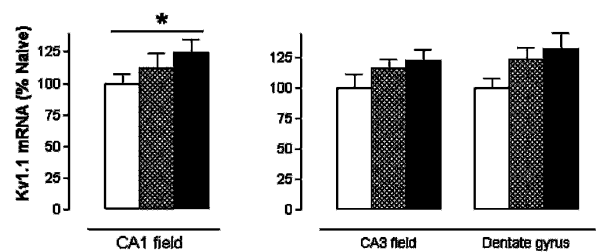

Dorsal hippocampus
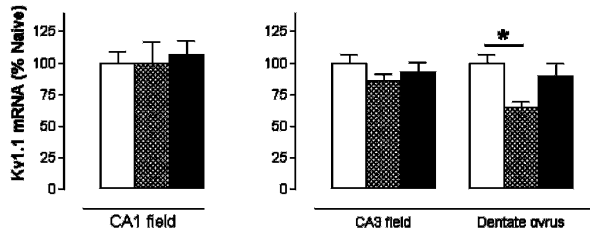

$\square$ Neive group Pseudoconditioned group $=$ Conditioned group

Figure 5. Kv1.1 subunit mRNA levels, measured $1 \mathrm{~h}$ after session 3 , for ventral and dorsal hippocampus regions. Data expressed as mean \pm S.E.M. Statistical significance: $\left(^{*}\right) P<0.05$ in ANOVA comparing the naive $(n=6)$, pseudoconditioned, $(n=5)$, and conditioned $(n=5)$ groups.

time, mRNA expression differed only occasionally between the pseudoconditioned and the naive group (Table 2). As there was no rule learning, there was a possibility that pseudoconditioned rats encountered a stressful environment compared with that of naive rats, which remained in the animal room. This environmental difference should have produced some variation in mRNA levels; furthermore, observations following session 3 showed no decrease in conditioned rats. It is worth noting that between sessions 2 and 3 the temporal analysis used revealed a significant increase in Kv1.1 mRNA for the pseudoconditioned group, suggesting a habituation of rats to their environment, whereas in the conditioned group, a significant decrease throughout training suggested a synaptic activation (Table 2). In a similar olfactory associative learning paradigm, polysynaptic field responses recorded in the dorsal dentate gyrus before and after training sessions increased dramatically immediately after session 2. In contrast, polysynaptic responses were unchanged prior to and immediately following session 3. Furthermore, this polysynaptic potentiation was correlated to learning (Chaillan et al. 1999). The decrease in Kv1.1 mRNA observed in the current study following session 2 and not session 3 may contribute to the dynamic activation of the hippocampal circuitry during associative information processing. On the contrary, in animals acclimatizing to random stimulus presentation (pseudoconditioned group), the increase of Kv1.1 mRNA levels may serve to inactivate neuronal networks in the ventral hippocampus and olfactory bulb. During similar olfactory task sessions, a synaptic depression developed in the dentate gyrus of pseudoconditioned animals, while long-term potentiation appeared in conditioned rats (Roman et al. 2004).

Regression analysis between Kv1.1 mRNA levels and behavioral learning revealed a positive correlation, suggesting that decreases in mRNA levels occur before the early two-odor learning process, as low differences between $\mathrm{S}+$ and $\mathrm{S}-$ latencies related to low mRNA levels, and high-latency differences to high mRNA levels. This down-regulation of Kv1.1 mRNA was transient and disappeared when the rats successfully discriminated between the odors during session 3. Gene expression regulation can occur at transcription, translation, or post-translational factor levels. cAMP level modulation may be one possible explanation for Kv1.1 mRNA down-regulation. Indeed, when cAMP levels were elevated in C6 glioma cells, Kv1.1 protein and the peak current amplitude of a delayed rectifier type of $\mathrm{K}^{+}$current were decreased. These were preceded by strong, rapid decreases in steady-state levels of Kv1.1 RNA $\left(t_{1 / 2}<3 \mathrm{~h}\right)$ resulting from a posttranscriptional destabilization of the transcript (Bosma et al. 1993; Mori et al. 1993; Allen et al. 1998; Matthias et al. 2002). Learning to associate a stimulus to a procedural behavior process (go or not go) for (or not) rat reinforcement may be related to receptor stimulation by neurotransmitter release in the hippocampus, and as a consequence, increase the cAMP level and subsequently decrease the Kv1.1 mRNA amount.

The contribution of Kv1.1 subunits to synaptic efficiency during information acquisition was reinforced by actual knowledge of the involvement of Kv1.1 channels in fine-tuning network excitability and the modulation of transmitter release. The Kv1.1 subunit is principally located in presynaptic sites, in the initial segment of the trapezoid body medial nucleus (MNTB) (Dodson et al. 2002), and in several CNS nerve terminals within transition zones between axons and the synaptic terminals (Wang et al. 1994; Veh et al. 1995; Rhodes et al. 1997; Monaghan et al. 2001). Kv1.1 subunits coassembled with Kv1.2 subunits constitute Kv1 heteromer channels responsible for low-threshold voltage-gated potassium currents $\left(\mathrm{I}_{\mathrm{LT}}\right)$ sensitive to low concentrations of dendrotoxin-I (Dodson and Forsythe 2004 ). The physiological function of the $\mathrm{I}_{\mathrm{LT}}$ current, activated around the threshold for action potential regeneration is to suppress hyperexcitability and reduce aberrant action potential generation. This is achieved by maintaining the membrane potential below threshold during small depolarizations, and by bringing the membrane back below threshold after single action potential. Dendrotoxin-K, which blocks channels containing Kv1.1, blocks

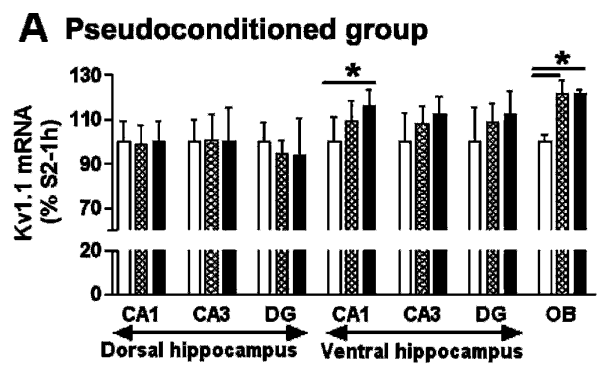

\section{B Conditioned group}

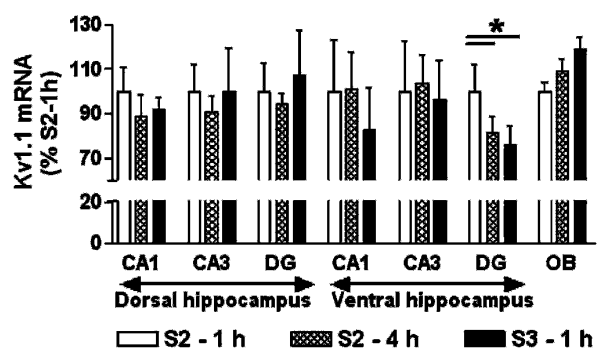

Figure 6. Temporal analysis. Kv1.1 subunit mRNA levels for olfactory bulb and dorsal and ventral hippocampus regions in the pseudoconditioned $(A)$ and conditioned groups $(B)$. Data expressed as mean \pm S.E.M. Statistical significance: $\left({ }^{*}\right) P<0.05$ in ANOVA comparing the different stages of learning, $1 \mathrm{~h}$ after session 2 ( $n=6$ and 7 for pseudoconditioned and conditioned group, respectively), $4 \mathrm{~h}$ after session $2(n=6$ and 6$)$, and $1 \mathrm{~h}$ after session 3 ( $n=5$ and 5$)$. 
the $\mathrm{I}_{\mathrm{LT}}$ current in MNTB neurons and generates multiple action potentials (Dodson et al. 2002). Moreover, Kv1.1 subunits coassembled with Kv1.4 or Kv1 $\beta$ subunits were also responsible for a transient current (A-type current) that permitted short-term spike threshold modulation, as well as action potential modulation duration. Cumulative inactivation of the A-type current using a sequence of stimuli results in presynaptic action potential broadening, and hence, transmitter release potentiation (in mossy fiber boutons in rat hippocampal slices [Geiger and Jonas 2000]; in neurohypophysial terminals [Jackson et al. 1991]). In the instance where mRNA level decrease reflects repressed protein synthesis, the Kv1.1 mRNA decrease, observed during the olfactory associative discrimination task may act to diminish threshold impact, voltage-gated potassium, and/or A type currents, and thus, contribute to the dynamic synaptic strength regulation during memory processing. As observed in the present study, Kv1.1 and Kv1.3 channel activity was inhibited by kaliotoxin in vivo, (which may have pharmacologically reinforced reduced Kv1.1 mRNA effects) during the olfactory discrimination task, where KTX-treated rats had better information acquisition performances (Kourrich et al. 2001).

Intracerebroventricular injections of Kv1.1 DNA antisense oligonucleotides reduce Kv1.1 mRNA (around 30\%) and induce a consistent spike waveform broadening in dentate granular cells in hippocampal slices. This was mainly attributed to a late rectifying $\mathrm{K}^{+}$current decrease in consequence, a prolonged repolar- ization phase and an after-hyperpolarization suppression (Meiri et al. 1997). Antisense inhibition of Kv1.1 impaired learning and memory for spatial and nonspatial contexts without affecting long term potentiation (Meiri et al. 1997; Gratacos et al. 1998). The induced reduction degree of Kv1.1 mRNA was similar to that found in the present study. However, the antisense knockdown was performed throughout training and affected the entire hippocampus, whereas a transient Kv1.1 mRNA reduction was found in only a few hippocampal fields. This difference might explain the comparison between the controls and the antisense treatment memory impairment observed. In mice lacking the Kv1.1 subunit, recordings from CA3 pyramidal cells showed normal action potential properties; however, orthodromic or antidromic stimulation could evoke synaptically driven bursts of action potential contrary to control, and suggests that the lack of Kv1.1 subunits can lead to synaptic hyperexcitability (Smart et al. 1998; Lopantsev et al. 2003). MNTB neurons recorded from mutant Kv1.1 knockout mice were found to be more excitable than those from wild-type controls. This may reflect a low voltage-activated $\mathrm{K}^{+}$current (half the amplitude of wild types), an increased firing frequency, or a reduced threshold for action potential generation (Brew et al. 2003). Taken together, the results of the present study suggest that Kv1 channels containing Kv1.1 subunits contribute to synaptic excitability modulation during learning and memory processes, and that this involvement is critical to the ventral hippocampus at the early learning stages.

\section{Ca1 field}
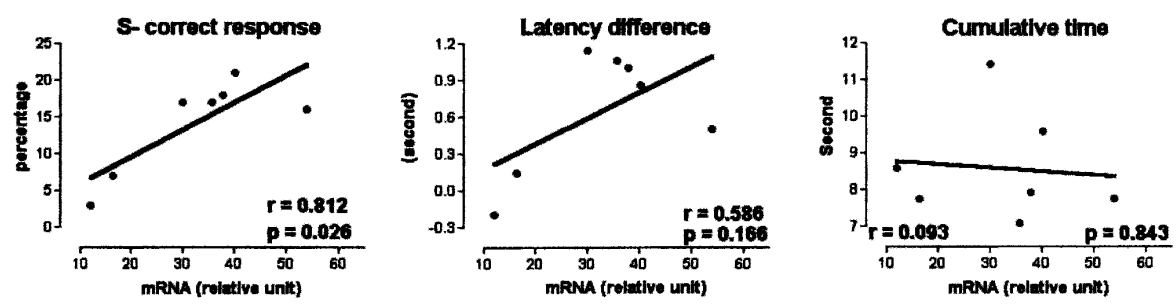

\section{CA3 field}
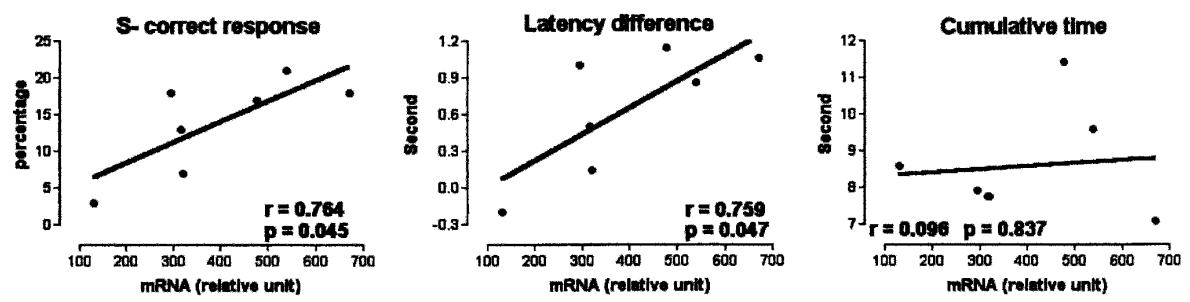

\section{Dentate gyrus}
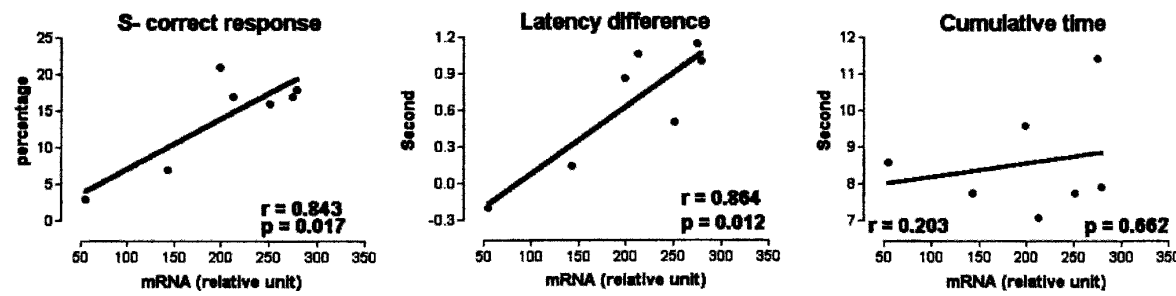

Figure 7. Relationships between the learning and Kv1.1 subunit mRNA levels measured $1 \mathrm{~h}$ after session 2 for the conditioned group in ventral hippocampus fields. Latency difference corresponds to differences between the $\mathbf{S}+$ stimulus latency and the $\mathrm{S}-$ stimulus latency. Correlations for Kv1.1 expression and $\mathrm{S}$ - latency could be established. Simple-linear regression analysis. Statistical significance: $P<0.05$.

\section{Materials and Methods}

\section{Animals}

Before olfactory associative learning and in situ hybridization, 52 male Sprague Dawley rats (280-300 g) (Charles River Company) were housed individually and given food and water ad libitum at a constant temperature $\left(22^{\circ} \mathrm{C}\right)$ under a 12 $\mathrm{h}$ light/12 $\mathrm{h}$ dark cycle (lights on at 7:00 a.m.). Each animal was handled (10 min) for $1 \mathrm{~d}$ before the behavioral experiment. These rats were divided into three experimental groups, one group of naive control animals that remained in the animal room, but were subjected to a water deprivation protocol $(n=18)$, a second group of pseudoconditioned rats $(n=17)$, and a third group of conditioned rats $(n=17)$. In the olfactory associative task, over a 2-d period, the pseudoconditioned and conditioned rats were handled again and put into experimental cages for experimental environment familiarization. The rats were deprived of water for $48 \mathrm{~h}$ prior to the first training session. On consecutive days, the rats were given water ad libitum for 30 min per day at 5:30 p.m.

\section{Olfactory associative task}

\section{Apparatus}

Discrimination training was conducted in a behavioral apparatus similar in design to Roman et al. (1993) and Kourrich et al. (2001). In brief, the apparatus was a rectangular box made of wire mesh $(30 \times 30 \times 50 \mathrm{~cm})$. A conical odor port $(1.5 \mathrm{~cm}$ in diameter, $0.5 \mathrm{~cm}$ above the floor) was drilled horizontally through a 
Table 2. Statistical significance

\begin{tabular}{|c|c|c|c|c|c|c|c|c|c|}
\hline \multicolumn{10}{|c|}{ Comparison of Kv1.1 mRNA levels between the groups } \\
\hline & \multicolumn{3}{|c|}{ Session 2-1 h } & \multicolumn{3}{|c|}{ Session 2-4 h } & \multicolumn{3}{|c|}{ Session 3-1 h } \\
\hline Comparison & C/PS & $\mathrm{C} / \mathrm{N}$ & $\mathrm{PS} / \mathrm{N}$ & C/PS & $\mathrm{C} / \mathrm{N}$ & $\mathrm{PS} / \mathrm{N}$ & C/PS & $\mathrm{C} /$ & PS $/ N$ \\
\hline \multicolumn{10}{|l|}{ Ventral hippocampus } \\
\hline Dentate gyrus & $\downarrow$ & & & & & & & & \\
\hline CA3 field & $\downarrow$ & & & & & & & & \\
\hline CA1 field & $\downarrow$ & $\downarrow$ & & & $\downarrow$ & & & $\uparrow$ & \\
\hline \multicolumn{10}{|l|}{ Dorsal hippocampus } \\
\hline Dentate gyrus & & & & & $\downarrow$ & & & & $\downarrow$ \\
\hline CA3 field & & & & & $\downarrow$ & & & & \\
\hline CA1 field & & & & & $\downarrow$ & & & & \\
\hline \multicolumn{10}{|l|}{ Temporal analysis } \\
\hline & \multicolumn{5}{|c|}{ Pseudoconditioned group } & \multicolumn{4}{|c|}{ Conditioned group } \\
\hline Comparison & $\begin{array}{l}\text { S2-1 } \\
\text { S2-4 }\end{array}$ & & $\begin{array}{l}\mathrm{S} 2-1 \mathrm{~h} / \\
\mathrm{S} 3-1 \mathrm{~h}\end{array}$ & $\begin{array}{l}\text { S2-4h } \\
\text { S3-1 h }\end{array}$ & & $\begin{array}{l}\mathrm{S} 2-1 \mathrm{~h} / \\
\mathrm{S} 2-4 \mathrm{~h}\end{array}$ & $\begin{array}{c}\text { S2-1 } \\
\text { S3-1 }\end{array}$ & & $\begin{array}{c}\text { S2-4 h/ } \\
\text { S3-1 h }\end{array}$ \\
\hline \multirow{2}{*}{\multicolumn{10}{|c|}{ Ventral hippocampus }} \\
\hline & & & & & & & & & \\
\hline Dentate gyrus & & & & & & $\downarrow$ & $\downarrow$ & & \\
\hline CA3 field & & & & & & & & & \\
\hline CA1 field & & & $\uparrow$ & & & & & & \\
\hline \multicolumn{10}{|l|}{ Dorsal hippocampus } \\
\hline \multicolumn{10}{|l|}{ Dentate gyrus } \\
\hline \multicolumn{10}{|l|}{ CA3 field } \\
\hline CA1 field & & & & & & & & & \\
\hline
\end{tabular}

(C) conditioned group; (PS) pseudoconditioned group; $(\mathrm{N})$ naive group.

triangular wedge of Plexiglas and mounted in one corner of the cage. A circular (1-cm diameter) water port in the shape of a well was placed directly above the odor port, and water-port responses were monitored by a photoelectric circuit. Two flashlight bulbs, which could be turned on and off as conditions required, were placed outside of the cage, one on each side of the odor and water ports, $10 \mathrm{~cm}$ above the floor.

Individual odors were delivered by forcing clean air $(0.7$ bars) through one of two Erlenmeyer flasks that contained 500 $\mathrm{mL}$ of water mixed with one of the chemicals or natural odors (Lavandin de Grignan). A "positive" odor ( $\mathrm{S}+$ ) flask was paired with a "negative" odor $(\mathrm{S}-$ ) flask. Nonodorized air was delivered by passing air through a flask that contained only water. Odorized and clean air streams were passed individually through tubes, which were put through the back of the sound-attenuating chamber and attached to the odor port. Water was delivered using a gravity feed system and was passed through a valve which, when opened, allowed $0.1 \mathrm{~mL}$ to be released into the water port. All procedural and behavioral events were recorded by microcomputers.

\section{Odor-reward training for conditioned animals}

Animals were trained to make two odor-reward associations. Each of the odors had to be associated with a specific reward; one odor (jasmine) was arbitrarily designated as positive and the other (strawberry) as negative, using a successive "go-no go" paradigm. Rats had to approach the odor and water ports to interrupt the light beam in front of them only when the positive odor was discharged for $10 \mathrm{sec}$. Response to the odor designated as negative resulted in a 10 -sec presentation of a nonaversive light. The water was distributed only with response to the positive odor.

Individual trials were presented in a quasi-random fashion, during which one of the odors was delivered for a maximum of 10 sec. A new trial was started only when the rat left the corner; if it did not, the trial was delayed for an additional $10 \mathrm{sec}$ (cumulative time). In no case did a new trial start earlier than $15 \mathrm{sec}$ after the end of either water or light delivery or a "no" response.
A daily session was made up of 60 trials with an intertrial interval of $15 \mathrm{sec}$. Animals were tested on three consecutive days between 8:00 a.m. and 3:00 p.m.

Correct responses were "go" for the positive odor and "no go" for the negative odor. Incorrect responses were "go" for the negative odor and "no go" for the positive odor. The number of correct responses to both positive and negative odors was expressed as a percentage of the total number of odor presentations. Latencies for positive $(\mathrm{S}+)$ and negative $(\mathrm{S}-$ ) odors were recorded, representing the time elapsed between the beginning of a trial and its end when the rat responded to the odor. If a rat did not respond, a latency of $10 \mathrm{sec}$ was scored. The percentage of correct responses and the latency were used to assess discriminative performance. In addition, because the subject could delay the trials by responding during the intertrial interval, the cumulative time was considered. The cumulative time was the number of seconds that exceeded the fixed 15-sec intertrial interval divided by the number of intertrial intervals in the experiment.

\section{Odor-reward training for pseudoconditioned animals}

Pseudoconditioned animals were prepared in the same way as conditioned animals. However, from sessions 1 to 3 , they experienced explicitly unpaired presentations of a positive odor, a negative odor, water, and light flashes. For each session, the odor stimuli was presented 30 times, and the number of water and light-flash presentations corresponded to the mean number of those accumulated during each session of the conditioned rats. Each of the four stimuli was presented in a quasi-random fashion. The duration of sessions 1-3 for pseudoconditioned animals was the mean duration of session for conditioned animals.

\section{Tissue preparation}

At the end of each training session, all rats were replaced in the animal room. Some of them from the three experimental groups (naive controls, pseudoconditioned, and conditioned) were anesthetized with pentobarbital sodic ( $6 \%$, Sanofi santé), decapitated at different times, $1 \mathrm{~h}$ after the second session, $4 \mathrm{~h}$ after the second session, and $1 \mathrm{~h}$ after the third session. These times were chosen when the rats had not learned the two-odor significance following the second session, but successfully discriminated between them after the third session. Rats were sacrificed $1 \mathrm{~h}$ after the second session when kaliotoxin (a toxin that inhibits the Kv1.1 $\alpha$-subunit) was found to improve associative learning following the same odor-reward training protocol (Kourrich et al. 2001). In addition, a 4-h time period was chosen, as it corresponded to the late stage of long-term potentiation, a model for memory processes related to protein synthesis and gene transcription (Bliss and Collingridge 1993; Izquierdo and Medina 1997). Brains were immediately removed, frozen on powered dry ice, and stored $\left(-80^{\circ} \mathrm{C}\right)$. Coronal sections $(12 \mu \mathrm{m})$ were cut in a cryostat at $-20^{\circ} \mathrm{C}$, thaw mounted on gelatin-coated slides, and stored at $-80^{\circ} \mathrm{C}$.

\section{Oligonucleotide probes}

An oligodesoxynucleotide probe for the rat Kv1.1 asubunit (50 mer) was purchased and purified by reverse-phase chromatography from Eurogentec S.A. The antisense sequence was 5'TGACCTGGA GCGGCCGAAGCCTCGTCTGCATTCTC CCCTGACATCACCGT-3' and was chosen to target the $5^{\prime}$-coding regions of the rat Kv1.1 $\alpha$-subunit mRNA at residues 4-53 of the published cDNA sequence (Baumann et al. 1988). The sense oligodeoxynucleotide was used as a negative control. The specificity of the probes was evaluated with the public domain program 
BLAST, and the sequences did not display any significant similarity with other sequences in databases. The probe cDNA fragments were prepared by labeling the cDNA fragment with the random primer method $\left[\alpha-{ }^{35} \mathrm{~S}\right] \mathrm{dATP}(1300 \mathrm{Ci} / \mathrm{mmol})$ using a DNA-tailing kit (NEN) and terminal deoxynucleotide transferase (Roche Diagnostics). The radiolabeled probes were then purified by phenolchloroform extraction and overnight precipitation in $100 \%$ ethanol at $-60^{\circ} \mathrm{C}$. After centrifugation, the radiolabeled probes were stored at $4^{\circ} \mathrm{C}$ in $20 \mathrm{mM}$ dithiothreitol at a specific activity (at least $1 \times 10^{6} \mathrm{cpm} / \mu \mathrm{L}$ ).

\section{In situ hybridization and autoradiography}

Because the quantification of the in situ hybridization signal requires analyzed brain section labeling to have been performed together, two in situ hybridization experiments were conducted. A first experiment collected brain sections of the three groups for each brain level and for one sacrifice time (i.e., $1 \mathrm{~h}$ after the second session, $4 \mathrm{~h}$ after the second session, and $1 \mathrm{~h}$ after the third session). A second experiment collected brain sections of the three sacrifice times for each brain level and for one group (i.e., naive control, pseudoconditioned, and conditioned rats). Both experiments were conducted using exactly the same in situ hybridization protocol.

All solutions used for in situ hybridization were treated with diethylpyrocarbonate and autoclaved to avoid RNase degradation. Slide-mounted sections were post-fixed for $5 \mathrm{~min}$ in 3\% paraformaldehyde and were rinsed twice (each wash lasting 5 min) in a phosphate saline buffer (PBS). The sections were then incubated in pre-hybridization buffer containing $2 \times$ standard saline citrate solutions (SSC) (twice, $5 \mathrm{~min}$ ) and $1 \times$ Denhardt's solution (30 min), then rinsed in $2 \times$ SSC $(10 \mathrm{~min})$. The sections were then acetylated for 10 min with $0.25 \%$ acetic anhydride in $0.1 \mathrm{M}$ triethanolamine and treated for $30 \mathrm{~min}$ in $0.1 \mathrm{M}$ Trisglycine before being dehydrated in ethanol and air dried.

For DNA probes, each section was covered with labeled probe $\left(5 \times 10^{5} \mathrm{cpm} / \mathrm{section}\right)$ diluted in $35 \mu \mathrm{L}$ of hybridization solution $(4 \times$ SSC containing 50\% formamide, $10 \%$ dextran sulfate, $1 \times$ Denhardt's solution, $5 \mathrm{mg} / \mathrm{mL}$ Escherichia coli tRNA, and $2.5 \mathrm{mg} / \mathrm{mL}$ sheared salmon sperm DNA) and incubated for $12 \mathrm{~h}$ at $42^{\circ} \mathrm{C}$ in humid chambers. Sections were then rinsed in cold $2 \times$ SSC, then treated successively with $1 \times$ SSC (room temperature, 10 and $40 \mathrm{~min})$, then in $1 \times \mathrm{SSC}\left(45^{\circ} \mathrm{C}, 10\right.$ and $\left.40 \mathrm{~min}\right)$ and in $0.1 \times \operatorname{SSC}\left(42^{\circ} \mathrm{C}, 15\right.$ and $\left.45 \mathrm{~min}\right)$. Sections were rinsed three times with $50 \%$ formamide in $2 \times \mathrm{SSC}\left(45^{\circ} \mathrm{C}, 5,20\right.$, and $\left.35 \mathrm{~min}\right)$ to decrease the background signal and in $1 \times$ SSC (room temperature, $3 \mathrm{~min}$ ). Sections were then dehydrated with a graded ethanol series and air dried.

Slides were exposed to Kodak Bio-Max MR-1 film for $11 \mathrm{~d}$. Exposure times were adjusted to avoid film saturation. The X-ray films were developed with Kodak GBX solution for 3 min at $20^{\circ} \mathrm{C}$, rinsed, and fixed. In the first experiment, same brain level sections from naive and experimental groups of animals for one learning stage were performed together in the same in situ hybridization and exposed side by side on the same autoradiographic film. In the second experiment, same brain level sections from different stages of learning for one experimental group were performed together in the same in situ hybridization and exposed side by side on the same autoradiographic film.

\section{Autoradiograms data analysis}

Film autoradiograms were scanned and the hybridization signal quantified using NIH image software by observers blind to the conditions of the experiment. The gray levels corresponding to mRNA-labeling levels were quantified using plastic standards $\left({ }^{14} \mathrm{C}\right.$, Amersham) to calibrate ${ }^{35} \mathrm{~S}$ relative concentration. mRNAlabeling levels are expressed in relative units. A mean level value was calculated for each brain structure of each hemisphere, from three unilateral measurements in each animal, and the mean \pm S.E.M. was then calculated. The rat brain regions were identified and named using the rat brain atlas of Paxinos and Watson (1986). No specific hybridization was observed in negative control sections (sense probe); i.e., these sections produced a weak, but uniform labeling signal that did not follow neuroanatomical landmarks (Fig.2).

\section{Statistical analysis}

Statistical analysis was performed with the SPSS/PC statistical 5.0 software by SPSS Inc. Differences between groups were assessed using an ANOVA followed by a Scheffé post hoc test to compare within multiple groups. Statistical significance for each analysis is indicated in the relevant results section. Simple-regression analysis was used to identify correlations between individual learning to changes in mRNA level. Significance was set at $P<0.05$.

\section{Acknowledgments}

We thank Michelle Bauget for assistance. We are grateful to Professor François Roman and Dr. Marie-France Martin-Eauclaire for discussions.

\section{References}

Allen, M.L., Koh, D-S., and Tempel, B.L. 1998. Cyclic AMP regulates potassium channel expression in C6 glioma by destabilizing Kv1.1 mRNA. Proc. Natl. Acad. Sci. 95: 7693-7698.

Alkon, D.L. 1984. Changes of membrane currents during learning. J. Exp. Biol. 112: 95-112.

. 1999. Ionic conductance determinants of synaptic memory nets and their implications for Alzheimer's disease. J. Neurosci. Res. 58: $24-32$.

Barnes, C.A., Eppich, C., and Rao, G. 1989. Selective improvement of aged rat short-term spatial memory by 3,4-diaminopyridine. Neurobiol. Aging 10: 337-341.

Baumann, A., Grupe, A., Ackermann, A., and Pongs, O. 1988. Structure of the voltage-dependent potassium channel is highly conserved from Drosophila to vertebrate central nervous systems. EMBO J. 7: 2457-2463.

Bliss, T.V.P. and Collingridge, G.L. 1993. A synaptic model of memory: Long-term potentiation in the hippocampus. Nature 361: 31-39.

Boland, L.M. and Jackson, K.A. 1999. Proteine kinase C inhibits Kv1.1 potassium channel function. Am. J. Physiol. 277: C100-C110.

Bosma, M.M., Allen, M.L., Martin, T.M., and Tempel B.L. 1993. PKA-dependent regulation of mKv.1.1, a mouse Shaker-like potassium channel gene when stably expressed in CHO cells. $J$. Neurosci. 13: 5242-5250.

Brew, H.M., Hallows, J.L., and Tempel, B.L. 2003. Hyperexcitability and reduced low threshold potassium currents in auditory neurons of mice lacking the channel subunit Kv1.1. J. Physiol. 548: 1.20.

Chaillan, F.A., Truchet, B., Roman, F.S., and Soumireu-Mourat, B. 1999. Early polysynaptic potentiation recorded in dentate gyrus during an associative learning task. Neuroscience 94: 443-451.

Coetzee, W.A., Amarillo, Y., Chiu, J., Chow, A., Lau, D., McCormack, T., Moreno, H., Nadal, M.S., Ozaita, A., Pountney, D., et al. 1999. Molecular diversity of $\mathrm{K}^{+}$channels. Ann. NY Acad. Sci. 868: 233-285.

Cowan, T.M. and Siegel, R.W. 1986. Drosophila mutations that alter ionic conduction disrupt acquisition and retention of a conditioned odor avoidance response. J. Neurogenet. 3: 187-201.

Cunningham, M.O. and Jones, R.S.G. 2001. Dendrotoxin sensitive potassium channels modulate GABA but not glutamate release in the rat entorhinal cortex in vitro. Neuroscience 3: 395-404.

Dodson, P.D. and Forsythe, I.D. 2004. Presynaptic $\mathrm{K}^{+}$channels: Electrifying regulators of synaptic terminal excitability. Trends Neurosci. 27: 210-217.

Dodson, P.D., Barker, M.C., and Forsythe, I.D. 2002. Two heteromeric Kv1 potassium channels differentially regulate action potential firing. J. Neurosci. 22: 6953-6961.

Drain, P., Dubin, A.E., and Aldrich, R.W. 1994. Regulation of Shaker K ${ }^{+}$ channel inactivation gating by the cAMP-dependent protein kinase. Neuron 12: 1097-1109.

Fournier, C., Kourrich, S., Soumireu-Mourat, B., and Mourre, C. 2001. Apamin improves reference memory but not procedural memory in rats by blocking small conductance $\mathrm{Ca}^{2+}$-activated $\mathrm{K}^{+}$channels in an olfactory discrimination task. Behav. Brain Res. 121: 81-93.

Gall, C.M., Hess, U.S., and Lynch, G. 1998. Mapping brain networks engaged by, and changed by, learning. Neurobiol. Learn. Mem. 70: $14-36$.

Geiger, J.R.P. and Jonas, P. 2000. Dynamic control of presynaptic $\mathrm{Ca}^{+2}$ inflow by fast-inactivating $\mathrm{K}^{+}$channels in hippocampal mossy fiber boutons. Neuron 28: 927-939.

Giese, K.P., Storm, J.F., Reuter, D., Fedorov, N.B., Shao, L.R., Leicher, T., Pongs, O., and Silva, A.J. 1998. Reduced $\mathrm{K}^{+}$channel inactivation, 
spike broadening, and after-hyperpolarization in Kvß1.1-deficient mice with impaired learning. Learn. Mem. 5: 257-273.

Giese, K.P., Peters, M., and Vernon, J. 2001. Modulation of excitability as a learning and memory mechanism: A molecular genetic perspective. Physiol. Behav. 73: 803-810.

Gratacos, E., Ghelardini, C., Gherardini, L.M., Galeotti, N., Murphy, K.J., Bartolini, A., and Regan, C.M. 1998. Kv1.1 channel antisense attenuates learning and modulation of dentate polysialylated NCAM. NeuroReport 9: 2727-2731.

Grissmer, S., Nguyen, A.N., Aiyar, J., Hanson, D.C., Mather, R.J. Gurman, G.A., Karmilowicz, M.J., Auperin, D.D., and Chandy, K.G. 1994. Pharmacological characterization of five cloned voltage-gated $\mathrm{K}^{+}$channels, types Kv1.1, 1.2, 1.3, 1.5, and 3.1, stably expressed in mammalian cell lines. Mol. Pharmacol. 45: 1227-1234.

Hallows, J.L. and Tempel, B.L. 1998. Expression of Kv1.1, a Shaker-liker potassium channel, is temporally regulated in embryonic neurons and glia. J. Neurosci. 18: 5682-5691.

Harvey, A.L. 2001. Twenty years of dendrotoxins. Toxicon 39: 15-26.

Hess, U.S., Lynch, G., and Gall, C.M. 1995. Changes in c-fos mRNA expression in rat brain during odor discrimination learning: Differential involvement of hippocampal subfields CA1 and CA3. J. Neuroscience 15: 4786-4795.

Izquierdo, I. and Medina, J.H. 1997. Memory formation: The sequence of biochemical events in the hippocampus and its connection to activity in other brain structures. Neurobiol. Learn. Mem. 68: $285-316$.

Jackson, M.B., Konnerth, A., and Augustine, G.J. 1991. Action potential broadening and frequency-dependent facilitation of calcium signals in pituitary nerve terminals. Proc. Natl. Acad. Sci. 88: 380-384

Kourrich, S., Mourre, C., and Soumireu-Mourat, B. 2001. Kaliotoxin, a Kv1.1 and Kv1.3 channel blocker, improves associative learning in rats. Behav. Brain Res. 120: 35-46.

Kues, W.A. and Wunder, F. 1992. Heterogeneous expression patterns of mammalian potassium channel genes in developing and adult rat brain. Eur. J. Neurosci. 4: 1296-1308.

Lopantsev, V., Tempel, B.L., and Schwartzkroin, P.A. 2003. Hyperexcitability of CA3 pyramidal cells in mice lacking the potassium channel subunit Kv1.1. Epilepsia 44: 1506-1512.

Manganas, L.N. and Trimmer, J.S. 2000. Subunit composition determines Kv1 potassium channel surface expression. J. Biol. Chem. 275: 29685-29693.

Matthias, K., Seifert, G., Reinhardt, S., and Steinhäuser, C. 2002. Modulation of voltage-gated channels Kv1.1 and Kv1.4 by forskolin. Neuropharmacology 43: 444-449.

Meir, A., Ginsburg, S., Butkevich, A., Kachalsky, S.G., Kaiserman, I., Ahdut, R., Demirgoren, S., and Rahamimoff, R. 1999. Ion channels in presynaptic nerve terminals and control of transmitter release. Physiol. Rev. 79: 1019-1088.

Meiri, N., Ghelardini, C., Tesco, G., Galeotti, N., Dahl, D., Tomsic, D., Cavallaro, S., Quattrone, A., Capaccioli, S., Bartolini, A., et al. 1997. Reversible antisense inhibition of Shaker-like Kv1.1 potassium channel expression impairs associative memory in mouse and rat. Proc. Natl. Acad. Sci. 94: 4430-4434.

Monaghan, M.M., Trimmer, J.S., and Rhodes, K.J. 2001. Experimental localization of Kv1 family voltage-gated $\mathrm{K}^{+}$channel $\alpha$ and $\beta$ subunits in rat hippocampal formation. J. Neurosci. 21: 5973-5983.

Mori, Y., Matsubara, H., Folco, E., Siegel, A., and Koren, G. 1993. The transcription of a mammalian voltage-gated potassium channel is regulated by cAMP in a cell-specific manner. J. Biol. Chem. 268: 26482-26493.

Paxinos, G. and Watson, C. 1986. The rat brain in stereotaxic coordinates.
Academic Press, New York.

Rhodes, K.J., Strassle, B.W., Monaghan, M.M., Bekele-Arcuri, Z., Matos, M.F., and Trimmer, J.S. 1997. Association and colocalization of the $\mathrm{Kv} \beta 1$ and $\mathrm{Kv} \beta 2 \beta$-subunits with $\mathrm{Kv} 1 \alpha$-subunits in mammalian brain $\mathrm{K}^{+}$channel complexes. J. Neurosci. 17: 8246-8258.

Robertson B. 1997. The real life of voltage-gated $\mathrm{K}^{+}$channels: More than model behaviour. Trends Pharmacol. Sci. 18: 474-483.

Roman, F.S., Simonetto, I., and Soumireu-Mourat, B. 1993. Learning and memory of odor-reward association: Selective impairment following horizontal diagonal band lesions. Behav. Neurosci. 107: 72-81.

Roman, F.S., Truchet, B., Chaillan, F.A., Marchetti, E., and Soumireu-Mourat, B. 2004. Olfactory associative discrimination: A model for studying modifications of synaptic efficacy in neuronal networks supporting long-term memory. Rev. Neurosci. 15: 1-17.

Saar, D., Grossman, Y., and Barkai, E. 1999. Reduced synaptic facilitation between pyramidal neurons in the piriform cortex after odor learning. J. Neurosci. 19: 8616-8622.

Sanchez-Andres, J.V. and Alkon, D.L. 1991. Voltage-clamp analysis of the effects of classical conditioning on the hippocampus. $J$. Neurophysiol. 65: 796-807.

Schreurs, B.G., Gusev, P.A., Tomsic, D., Alkon, D.L., and Shi, T. 1998. Intracellular correlates of acquisition and long-term memory of classical conditioning in Purkinje cell dendrites in slices of rabbit cerebellar lobule HVI. J. Neurosci. 18: 5498-5507.

Sheng, M., Liao, Y.J., Jan, Y.N., and Jan, L.Y. 1993. Detection of heteromultimeric $\mathrm{K}^{+}$channels in vivo: Potential molecular basis of a presynaptic A-current. Nature 365: 72-75.

Sheng, M., Tsaur, M.L., Jan, Y.N., and Jan, L.Y. 1994. Contrasting subcellular localization of the $\mathrm{Kv} 1.2 \mathrm{~K}^{+}$channel subunit in different neurons of rat brain. J. Neurosci. 14: 2408-2417.

Smart, S.L., Lopantsev, V., Zhang, C.L., Robbins, C.A., Wang, H., Chiu, S.Y., Schwartzkroin, P.A., Messing, A., and Tempel, B.L. 1998 Deletion of the Kv1.1 potassium channel causes epilepsy in mice. Neuron 20: $809-819$.

Song, W.J. 2002. Genes responsible for native depolarization-activated $\mathrm{K}^{+}$currents in neurons. Neurosci. Res. 42: 7-14.

Stühmer, W., Ruppersberg, J.P., Schröter, K.H., Sakmann, B., Stocker, M., Giese, K.P., Perschke, A., Baumann, A., and Pongs, O. 1989 Molecular basis of functional diversity of voltage-gated potassium channels in mammalian brain. EMBO J. 8: 3235-3244.

Truchet, B., Chaillan, F.A., Soumireu-Mourat, B., and Roman, F.S. 2002. Early integrative processes physiologically observed in dentate gyrus during an olfactory associative training in rat. J. Int. Neurosci. 1: 101-115.

Veh, R.W., Lichtinghagen, R., Sewing, S., Wunder, F., Grumbach, I.M., and Pongs, O. 1995. Immunohistochemical localization of five members of the Kv1 channel subunits: Contrasting subcellular locations and neuron-specific co-localizations in rat brain. Eur. J. Neurosci. 7: 2189-2205.

Wang, H., Hunkel, D.D., Schwartzkroin, P.A., and Tempel, B.L. 1994. Localization of Kv1.1 and Kv1.2, two K channel proteins, to synaptic terminals, somata, and dendrites in the mouse brain. J. Neurosci. 14: 4588-4599.

Winklhofer, M., Matthias, K., Seifert, G., Stocker, M., Sewing, S., Herget, T., Steinhäuser, C., and Saaler-Reinhardt, S. 2003. Analysis of phosphorylation-dependent modulation of Kv1.1 potassium channels. Neuropharmacology 44: 829-842.

Received September 13, 2004; accepted in revised form June 28, 2005. 


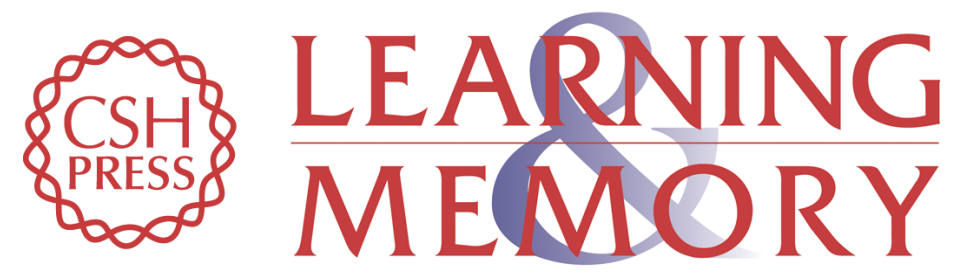

\section{Transient hippocampal down-regulation of Kv1.1 subunit mRNA during associative learning in rats}

Saïd Kourrich, Christine Manrique, Pascal Salin, et al.

Learn. Mem. 2005, 12:

Access the most recent version at doi:10.1101/lm.86305

References This article cites 52 articles, 18 of which can be accessed free at: http://learnmem.cshlp.org/content/12/5/511.full.html\#ref-list-1

License

Email Alerting Receive free email alerts when new articles cite this article - sign up in the box at the Service top right corner of the article or click here. 